\title{
IMPLEMENTATION OF RADIO FREQUENCY IDENTIFICATION TECHNOLOGY IN ACCESSING INFORMATION IN HOSPITALS
}

\author{
Megha Satish', Sukhwant Kaur ${ }^{2}$, S. K. Pandey ${ }^{3}$ \\ ${ }^{1}$ Student, School of Engineering and Information Technology, Manipal University, Dubai, U.A.E \\ ${ }^{2}$ Assistant Professor, School of Engineering and Information Technology, Manipal University, Dubai, U.A.E \\ ${ }^{3}$ Professor, School of Engineering and Information Technology, Manipal University, Dubai, U.A.E
}

\begin{abstract}
In today's fast paced world with an enhancement of technology and innovation, healthcare systems have become so advanced with their technologies to monitor health variations. The prominent issue common man faces today is the number hours we spend in queues. This problem is not just for hospitals, but applies to every sector such as education, restaurants, malls, etc. Besides the issue mentioned above, there is another concern that we face with traditional filing system that are followed in many organizations. Loss of information has come into the radar of research, with the advancement of technologies and various ways to access them. Preservation and security of confidential information and data is expensive and requires skill to maintain them. Technology enhancement has made RFID technology more affordable over the years and is still a secure way to control the information and the usage of this technology hasn't been explored enough. This system can be implemented as a module in any management system or security based system to allow or restrict access to any information.
\end{abstract}

In order to resolve the above issues we integrated a database to secure confidential information with an easy and user friendly interface to be used by the hospital staff. RFID cards can control the access and manipulation of data. The application software for desktops integrates a RFID reader to enable easier access of information from the database, in this case the medical records and patient data. In this paper we describe the successful implementation and integration of the RFID reader with the application and the methodology that has been implemented to achieve a successful outcome.

Keywords: Health Care, Radio Frequency Identification Tags (RFID), Passive and Active Tags, Low Frequency Tags, High Frequency Tags, Ultra High Frequency Tags

\section{INTRODUCTION}

A Hospital Information System is an element of health informatics that focuses mainly on the administrational needs of hospitals. In many implementations, a HIS is a comprehensive, integrated information system designed to manage all the aspects of the hospitals options such as medical, administrative, financial and legal issues and the corresponding processing of services.

The purpose of the application is to assist hospital staff in tracking and maintaining patient records over a period of time. Also patients can save time by not standing in long queues at the front desk to retrieve their files before seeing the doctor. Besides saving time at the hospitals, the benefits the patients can have are the consistent and updated records. This will help them review their issues with the doctors and also have secure database of their medical records.

The rest of the paper is organized as follows, Section 2 gives an insight about the various types of tags and about the RFID reader. Section 3 explains the design of problem statement. Section 4 gives a brief analysis of the methodology used. Section 5 demonstrates the implementation results. Section 6 shows the issues faced during implementation of the application. Sections 7 will illustrate the future scope of the application in real world.

\section{RFID READER AND TAGS}

\subsection{Introduction}

Radio-frequency identification (RFID) is the wireless use of electromagnetic fields to transfer data, for the purposes of automatically identifying and tracking tags attached to objects. Some tags are powered by electromagnetic induction from magnetic fields produced near the reader. Other types have a local power source such as a battery and may operate at hundreds of meters from the reader [2].

RFID advantages can be briefly explained as follows:

- $\quad$ Reader can read and write data to RFID tags without direct contact and no line of sight problem.

- Data from the multiple RFID tags are accessed by the reader by radio waves.

- Fast read and write with the time taken for read/write being a few milliseconds.

- Modern RFID tags are made with very good memory capacities ranging from 16 - 64 Kbytes which is many times more than a typical barcode. 
- $\quad$ RFID tags can work with GPRS and has been used for tracking.

- $\quad$ RFID tags can also integrate with other technologies. For example, it is used with wireless sensor networks for better connectivity [4] [5].

\subsection{Passive and Active Tags}

Radio Frequency Identification (RFID) is similar to the barcode systems but RFID reader use radio waves to recognize and capture information from the RFID tags.

RFID tags consist of an integrated circuit(IC) and an antenna. This is packaged in a protective plastic packing like in a card form (Fig 1). These tags come in two types:

- $\quad$ Active tags: They consist of a self powered battery and send out radio signals to find the matching reader. They come in Read- Only and in Read- Write format. These are considerably more costly than the passive tags.

- $\quad$ Passive tags: These tags do not have battery and also come in Read- Only and in Read- Write format [9]. Passive RFID also have advantages of long life and being small enough to fit into a practical adhesive label. Hence passive RFID tags are used for many applications. A passive RFID tag consists of mainly three parts: an antenna, a semiconductor chip attached to the antenna, and some encapsulation to protect the tag from the environment. Passive RFID tags don't carry any powered device and became active only upon exposure to external energy. The RFID reader does the work for activating and communicating with the tag. The passive RFID tag antenna captures energy from the reader and is responsible for communicating the data between tag and reader [4].

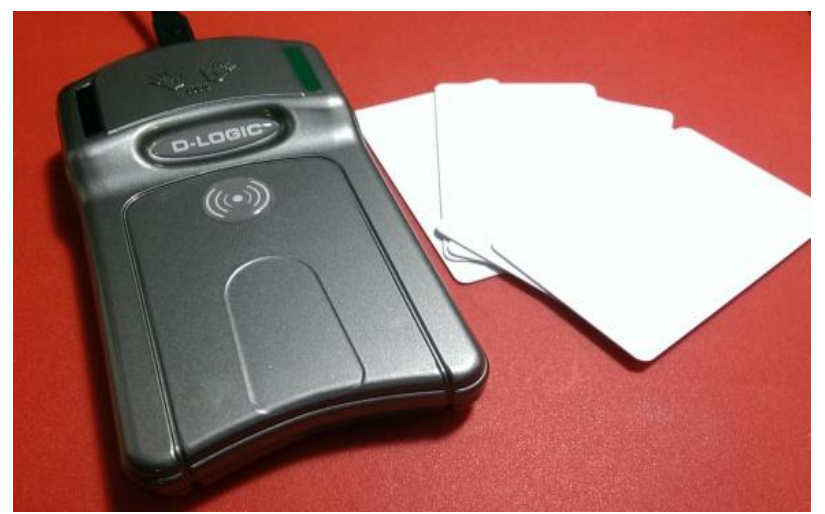

Fig 1: RFID reader and passive tags from D-Logic (Device used in this application)

\subsection{RFID Frequency}

RFID tags fall into three regions in respect to frequency:

- $\quad$ Low frequency $(\mathrm{LF}, 30-500 \mathrm{kHz}$ ): Low frequency tags are cheaper than any of the higher frequency tags. They are fast enough for most applications, however for larger amounts of data the time a tag has to stay in a readers range will increase. Another advantage is that low frequency tags are least affected by the presence of fluids or metal. The disadvantage of such tags is their short reading range. The most common frequencies used for low frequency tags are 125 $134.2 \mathrm{kHz}$ and $140-148.5 \mathrm{kHz}$.

- $\quad$ High frequency (HF, $10-15 \mathrm{MHz})$ : High frequency tags have higher transmission rates and ranges but also cost more than LF tags. Smart tags are the most common member of this group and they work at $13.56 \mathrm{MHz}$.

- Ultra high frequency (UHF, $850-950 \mathrm{MHz}, 2.4$ $2.5 \mathrm{GHz}, 5.8 \mathrm{GHz}$ ): UHF tags have the highest range of all tags. It ranges from 3-6 meters for passive tags and $30+$ meters for active tags. In addition the transmission rate is also very high, which allows to read a single tag in a very short time. This feature is important where tagged entities are moving with a high speed and remain only for a short time in a readers range. UHF tags are also more expensive than any other tag and are severely affected by fluids and metal. Those properties make UHF mostly useful in automated toll collection systems. Typical frequencies are $868 \mathrm{MHz}$ (Europe), $915 \mathrm{MHz}$ (USA), 950MHz (Japan), and 2.45GHz [3].

Frequencies for LF and HF tags are license exempt and can be used worldwide; however frequencies for UHF tags differ from country to country and require a permit [5][8].

In this proposed application we have made use of the LF tags.

\subsection{Security}

There are various security mechanisms for securing the radio frequencies

- Kill command: The command will render the tag unusable once received. To prevent an adversary to call those commands they are password protected.

- $\quad$ Sleep command: A tag cannot always be killed. The sleep command works similar to the kill command. Once received the only command accepted is the password protected wakeup command.

- Relabeling: Describes an approach where the customer can re-label the item tag with a string of user's choice. Some of the old information however remains in a password protected area.

- $\quad$ Split approach: This approach allows item tracking by its unique identifier and still allows the customer to keep track of its own items.

- Proxy approach: Describes the RFID guardian. It assumes that all tags are protected by a PIN that the user can set. Once an item is bought the guardian sets a new PIN. If another reader wants to have access to the data, the reader requests that information from the guardian which retrieves it from the tag and forwards it to the reader if the reader is authorized.

- Distance approach: Tags use the signal-to-noise ratio to get a rough estimate of the readers distance. The closer the reader, the more information is released. 
- Blocking approach: In this application we will be using the blocking approach. RFID tags use a special protocol that controls the access to the shared medium (air). When a reader is in an area with multiple tags it first discovers all tags in its range and then it polls each of the tags [1] [8].

\section{DESIGNING PROBLEM STATEMENT}

According to the express newspaper of the UK, we spend nearly 80 hours a year just queuing up in places to get our services [6]. According to a study commissioned by the Ministry of Social Affairs and Health Insurance Fund found that long queues are the biggest worry for patients using the nation's health care systems and people are willing to spend extra and to skip ahead of the lines. 45 percent of the respondents of the survey named long waiting times as the most pressing problem [7].

Healthcare is one of the most important part of a society. Development and advancements in the health sector of a community can add to the development of the society. Each day thousands of patients use healthcare facilities and challenge the administration to run all functions smoothly. Previously, all records were manually stored in file systems and in large file rooms. When a patient arrives they ask or their file number and they retrieve the records. Now with the help of a similar file number they can retrieve all data such as personal records, medical and even results of tests and scans.

This system is allowing health care providers to do their tasks and jobs more efficiently and effectively. These systems can be modified and altered as the growth of the organization improves. A good information system can provide benefits such as:

- Enhances information integrity

- Reduces transcription errors

- Reduces duplication of information entries

- $\quad$ Optimizes report turnaround times

Modern hospital typically uses fast computers that can be connected to one another through optimized networks such as LAN's. These systems are programmed to collect process and retrieve patient information and utilize it for administrative and medical purposes. Information systems are generally customized to the user's needs and will every from customer to customer. HIS can be customized to suit the user groups and can have more user friendly and multilingual interfaces to suit the diverse workforce [8].

\subsection{Modular Structure of the Application}

Every RFID tags has a unique hexadecimal number that identifies the tag as an individual and unique tag to the reader. Using this, each tag is allotted to one patient. In the hospital's database each patient is identified uniquely using the RFID number. The following diagrams shows a concept structure of the application.
Fig 2 demonstrates the overall flow of the application. There are 4 segments designed in the concept application, such as Receptionist, Doctor, Pharmacist and DBA The following flowcharts (Fig 3,4,5,6) demonstrates the individual flow of each module [2].

The basic flow of the application starts when the receptionist tags the patients RFID tag, each RFID tag is identified using a unique number that is built into the tag. This unique number identifies the patient as a registered patient of the hospital. This allows the receptionist to allot appointments for to the right patient (Fig 3).

If the patient has arrived due to an appointment, the patient walks in to the doctor's office. The doctor scans the RFID card and all the information will be retrieved from the database, the doctor can update and modify the information (Fig 4).

The pharmacist follows the same procedure to get access to the patient's medication list prescribed by the doctor (Fig $5)$.

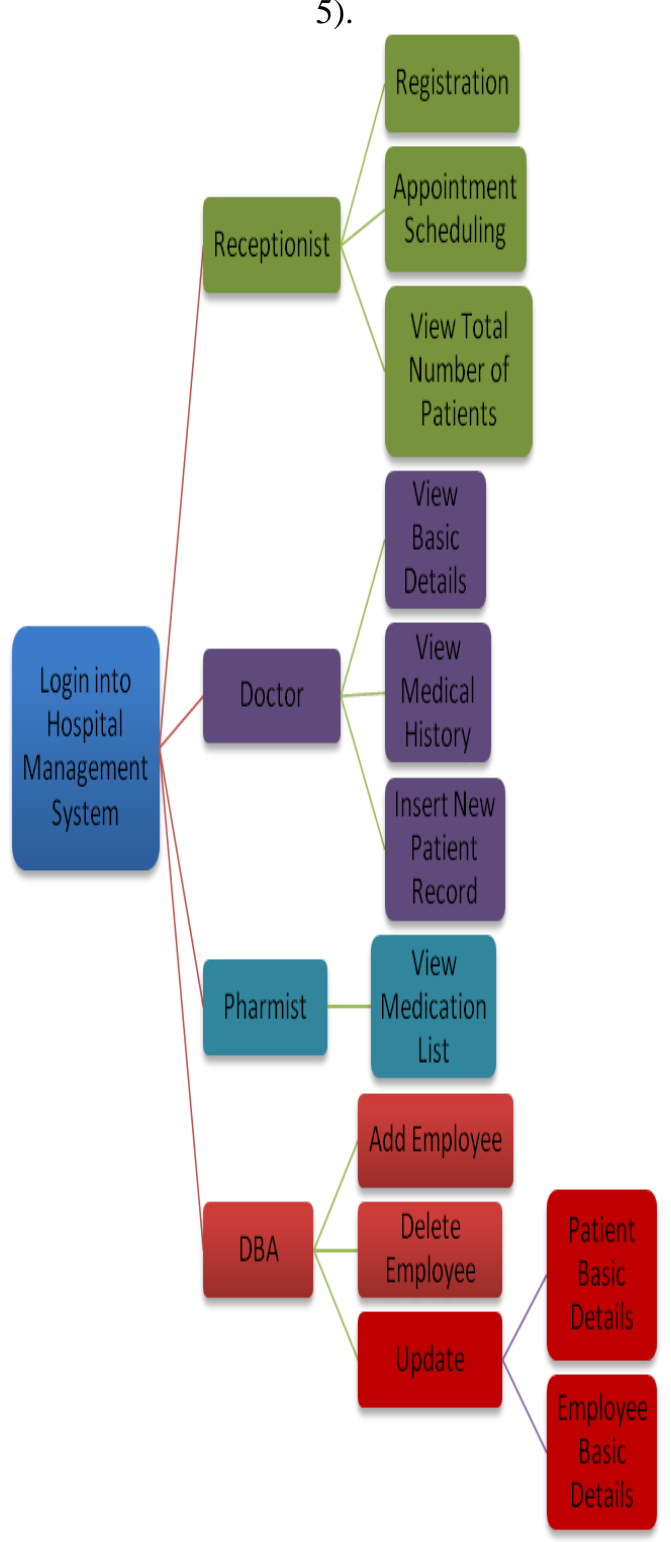

Fig 2: Application Overview 


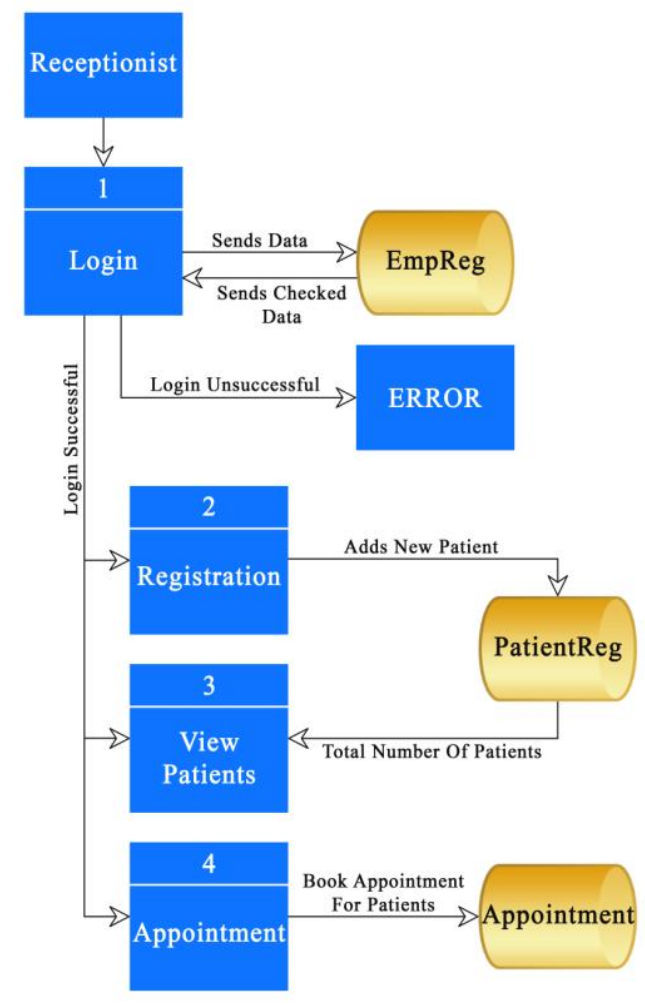

Fig 3: Data Flow of the Receptionist Module

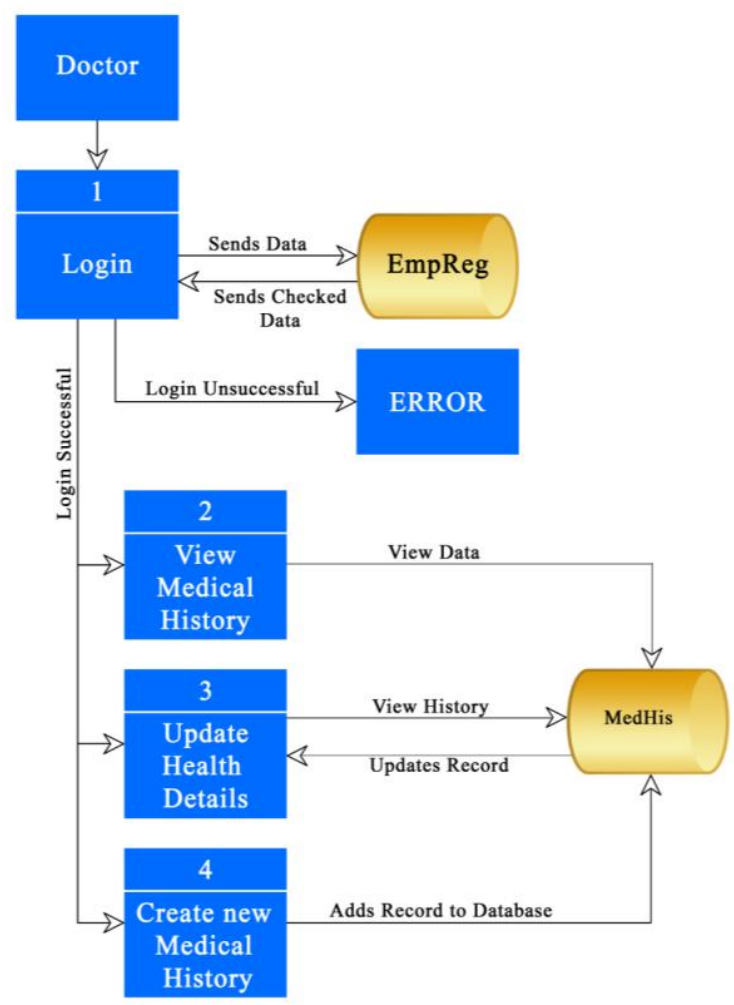

Fig 4: Data Flow of the Doctor Module

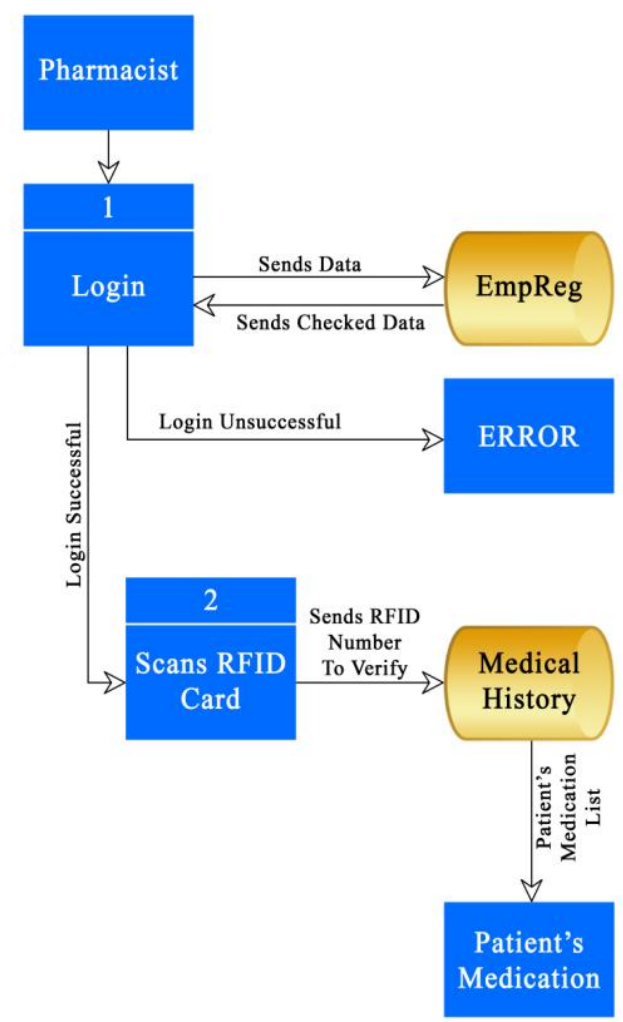

Fig 5: Data Flow of the Pharmacist Module

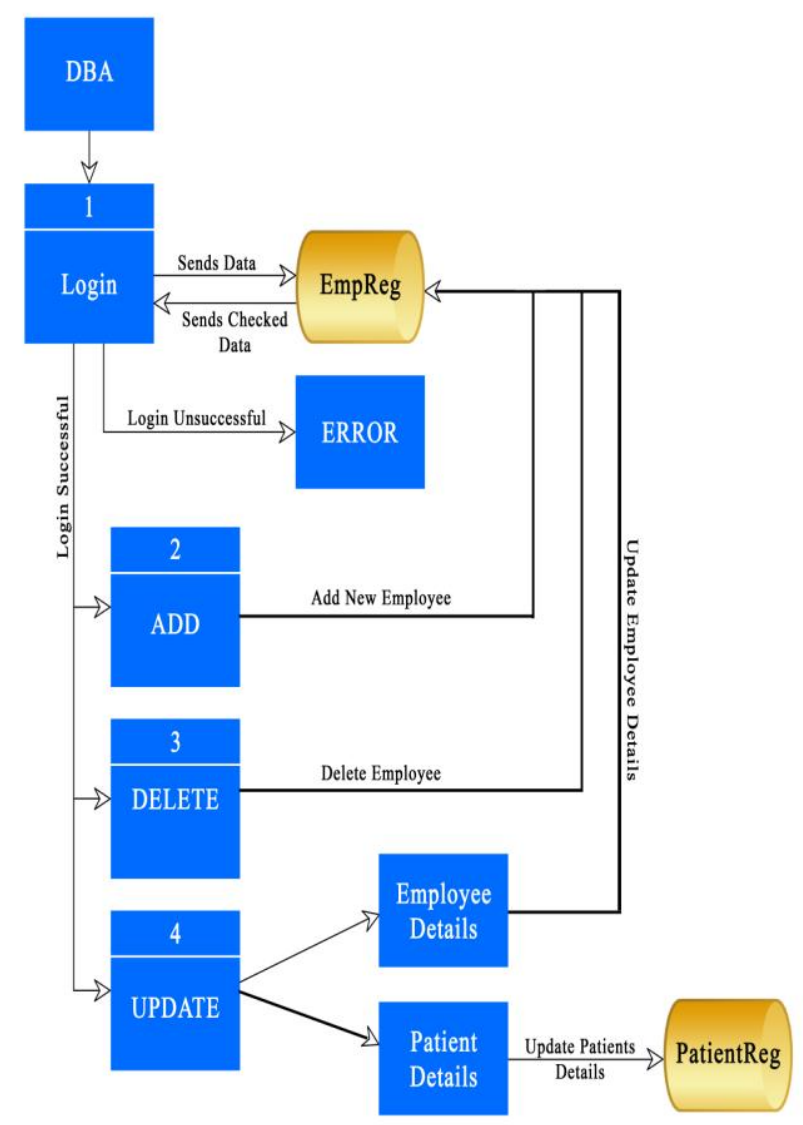

Fig 6: Data Flow of the DBA Module 


\section{METHODOLOGY USED}

In this application, SDLC is being used for its implementation. It is a framework defining tasks performed at each step in the software development process. It consists of a detailed plan describing how to develop, maintain and replace specific software. The life cycle defines a methodology for improving the quality of software and the overall development process [10].

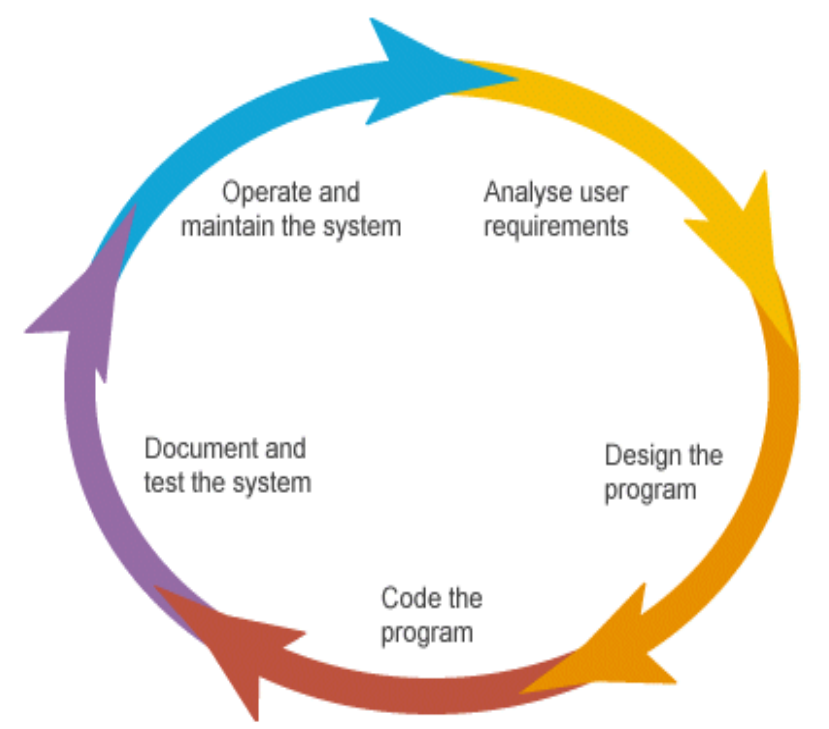

Fig 7: Software Development Life Cycle

Below are the Hardware and Software and System specification used to implement this application.

Software Used:

- IDE: Netbeans 7.4

- Programming Language: Java

- Database: MySQL

System Specifications Used:

- Operating System : Windows 8.1 ( Anything above Windows7)

- $\quad$ RAM: 4GB

- $\quad$ Storage: $2 \mathrm{~GB}$ and above

Hardware Requirements:

- $\quad$ RFID Reader ( RDIF Reader from dLogic is used in this application)

- $\quad$ RFID enabled cards

\section{IMPLEMENTATION RESULTS}

\subsection{Database Implementation}

\subsubsection{Employee Type}

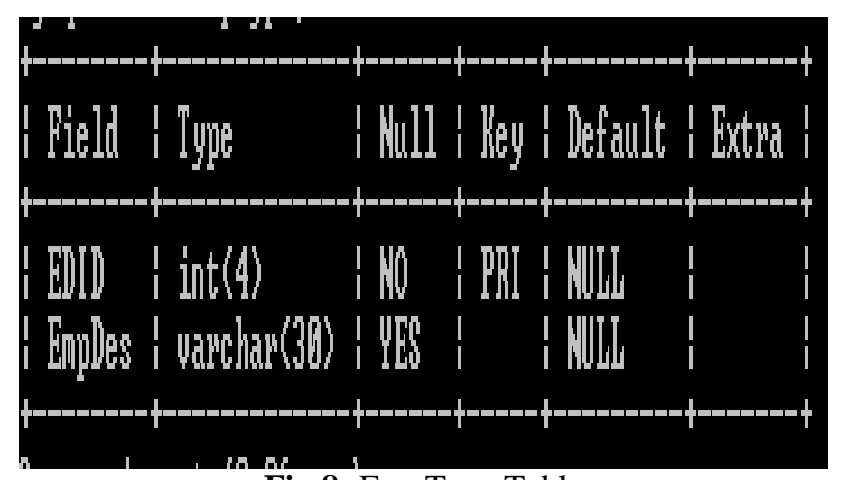

Fig 8: EmpType Table

\subsubsection{Employee Registration}

\begin{tabular}{|c|c|c|c|c|}
\hline Field & I Type & I Null & I Key I Default & | Extra | \\
\hline EnplD & 1 int $(4)$ & I No & | PRI | NULL & | \\
\hline First Wame & | varchar $(10)$ & I YES & I I NULL & i \\
\hline LastKame & | varchar(10) & I YES & I NULL & I \\
\hline Userkame & | varchar (10) & I YES & I NULL & ! \\
\hline Password & I varchar(20) & I YES & I NULL & I \\
\hline $\mathrm{DOB}$ & I date & I YES & I NULL & i \\
\hline Gender & I char(1) & I YES & I NULL & I \\
\hline Mobile & I int(10) & I YES & I NULL & i \\
\hline email & I varchar (30) & I YES & I NULL & ! \\
\hline Bloodgroup & | varchar(3) & I YES & I NULL & i \\
\hline EDID & 1 int $(4)$ & I YES & I NULL & i \\
\hline Salary & I float $(6,2)$ & I YES & I NULL & I \\
\hline $\mathrm{DOJ}$ & I date & I YES & I NULL & \\
\hline
\end{tabular}

Fig 9: EmpReg Table

\subsubsection{Patient Registration}

\begin{tabular}{|c|c|c|c|c|c|c|}
\hline Pield & I Thin & I lill] & I Hey & i lief: & & i \\
\hline & I valdar (10) & If & I Ph & 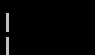 & 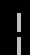 & 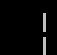 \\
\hline Pintipar. & I talder $(10)$ & 1 I & I & i r.ll] & I & | \\
\hline Intilane & I lakdar $(10)$ & I IES & i & i r illihis & f & i \\
\hline 101 & I dite & I & 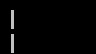 & I Flllih & i & i \\
\hline Gender & c cond & I IES & i & i lillli & i & i \\
\hline poble & 1 int $(10)$ & I If & I & i r lilli & i & \\
\hline elail & 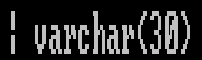 & I IE & i & i r lilli & 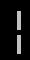 & \\
\hline Alondhintu & I valder $(\beta)$ & I If & I & i r lilli & | & \\
\hline
\end{tabular}

Fig 10: PatientReg Table 


\subsubsection{Appointment Table}

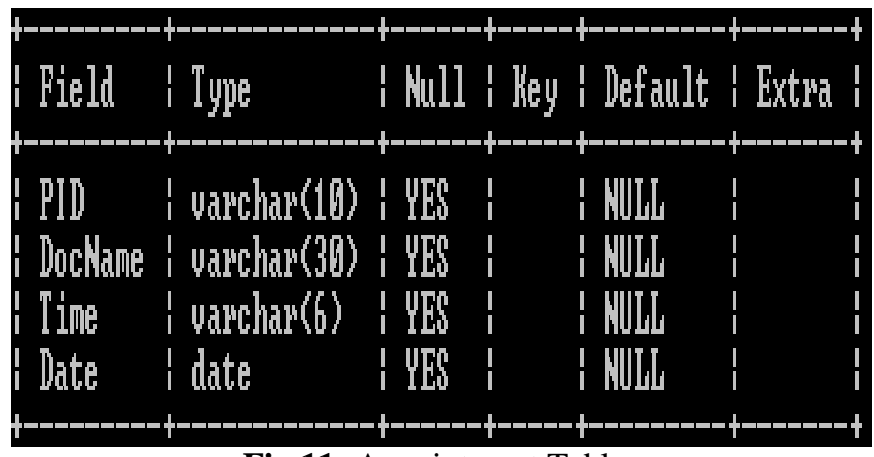

Fig 11: Appointment Table

\subsubsection{Medical History}

\begin{tabular}{|c|c|c|c|c|}
\hline Field & lype & Hill I Hey & lefault & I Extra \\
\hline Heiglit & $f \operatorname{loat}(4,1)$ & | $4 E_{0}^{\circ}$ & VWL & | \\
\hline Meiglit & Iflot $(5,2)$ & I I & 情U & i \\
\hline id & I varchar $(6)$ & YES & 怆山 & ! \\
\hline Henoglobin & $\operatorname{int}(3)$ & YES I & 怆W & ! \\
\hline lascrintion & varchar (2PI) & 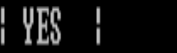 & 怆W & ! \\
\hline redication & varchar (20D) & 1460 & 阠山 & ! \\
\hline late & date & I IES | & 怆W & I \\
\hline PID & varchar(10) & YEO I & NWL & i \\
\hline
\end{tabular}

Fig 12: MedHis Table

\subsection{SCREENSHOTS OF THE APPLICATION}

\subsubsection{Login}

The Login page is for the Hospital staff such as front desk, doctors, etc. Each profession is designated with a user name and password. This helps to control the confidentiality of the patient's information; only doctors have permission to access the information

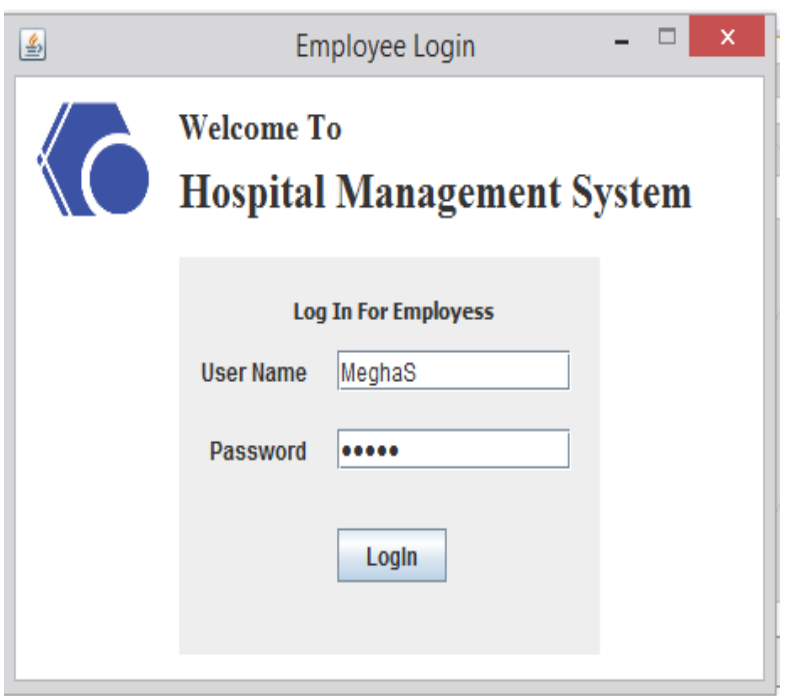

Fig 12: Login Page for Hospital Management System

\subsubsection{Reception}

When the receptionist (front desk) logs in and will have come to a screen where the receptionist has an option to register a new patient, make an appointment or just view all the existing patients in the hospital.

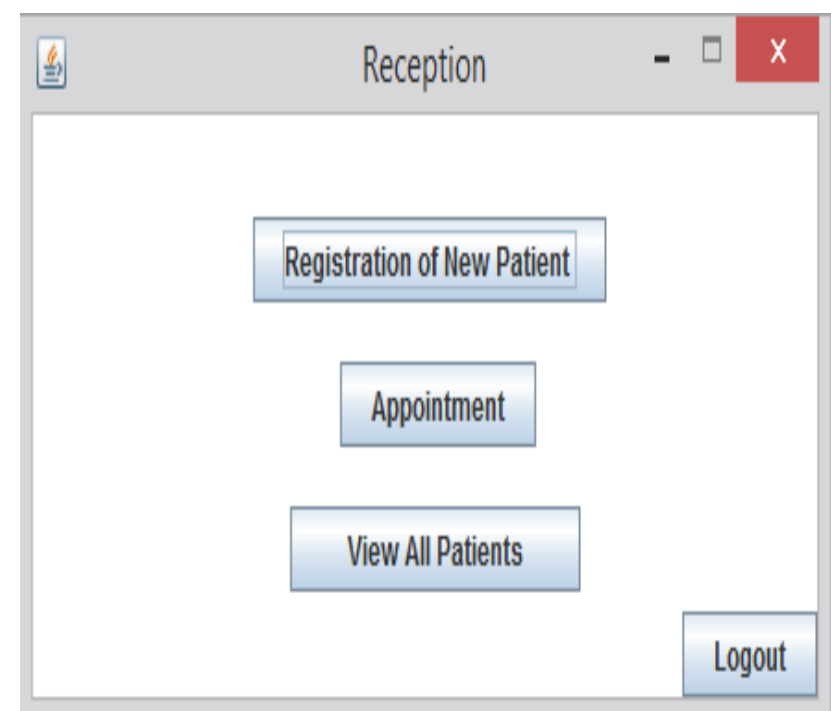

Fig 13: Reception Page

\subsubsection{Patient Registration}

The receptionist can register a new patient to the hospital database. The RFID number can be obtained when a new card is scanned on the RFID reader.

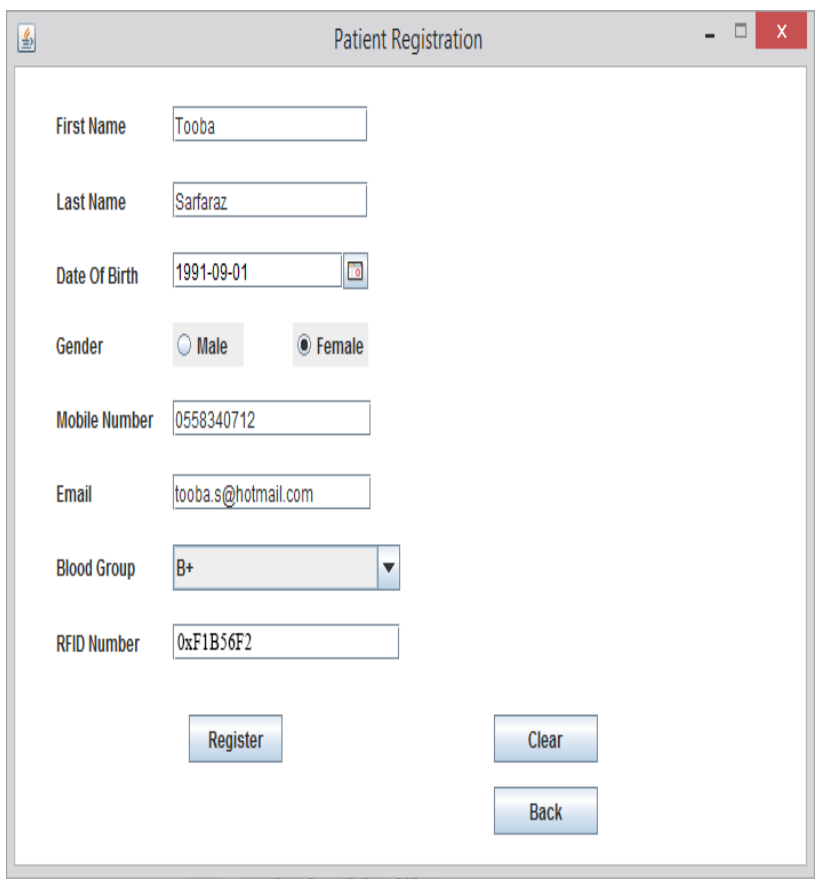

Fig 14: Patient Registration

\subsubsection{Patient Appointment}

The receptionist can assign appointments to patients using the RFID numbers. 


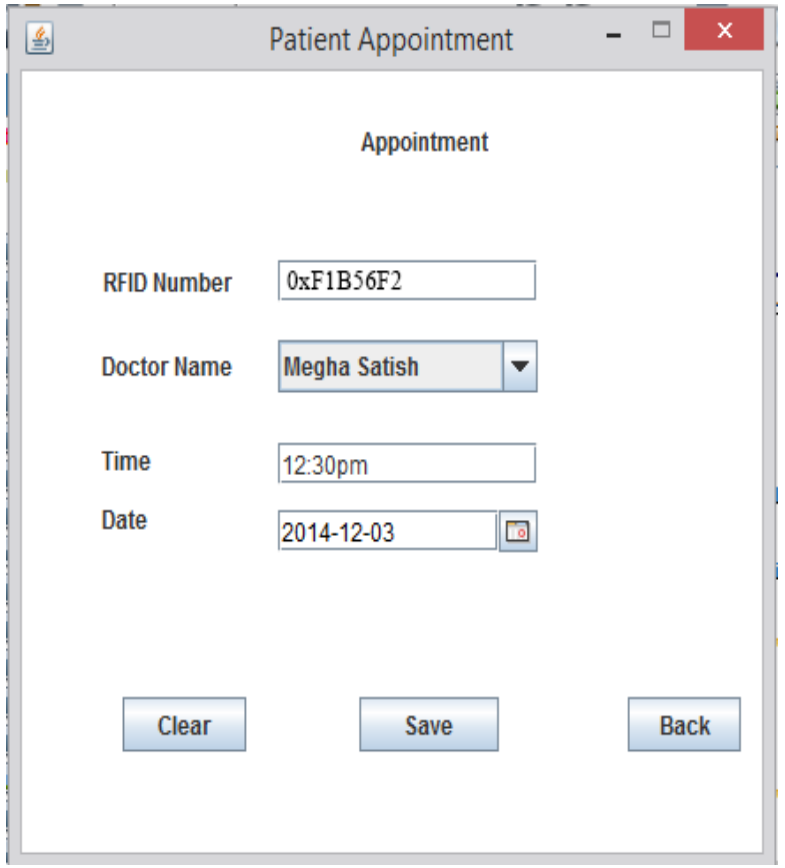

Fig 15: Patients Appointment

\subsubsection{View Registered Patients}

The receptionist can view all the existing patients in the hospitals database.

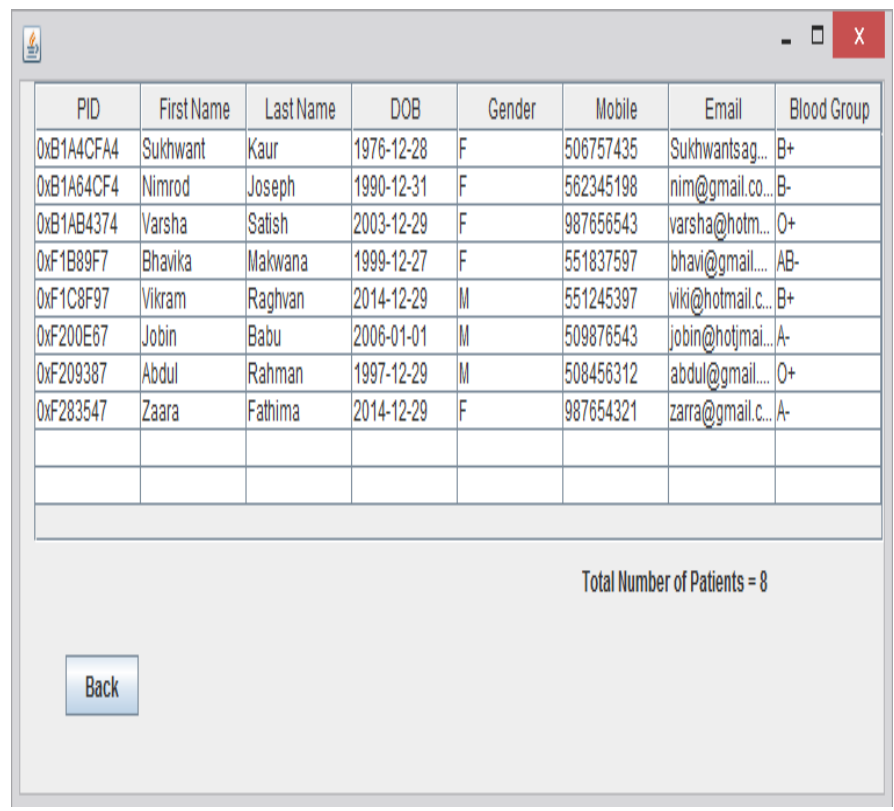

Fig 16: View all registered patients

\subsubsection{Doctor}

When the doctor logs in, they have to scan the patients RFID card, and the doctor clicks on search. All information of the patient such as the name, age, blood group, etc., will appear in those designated areas.

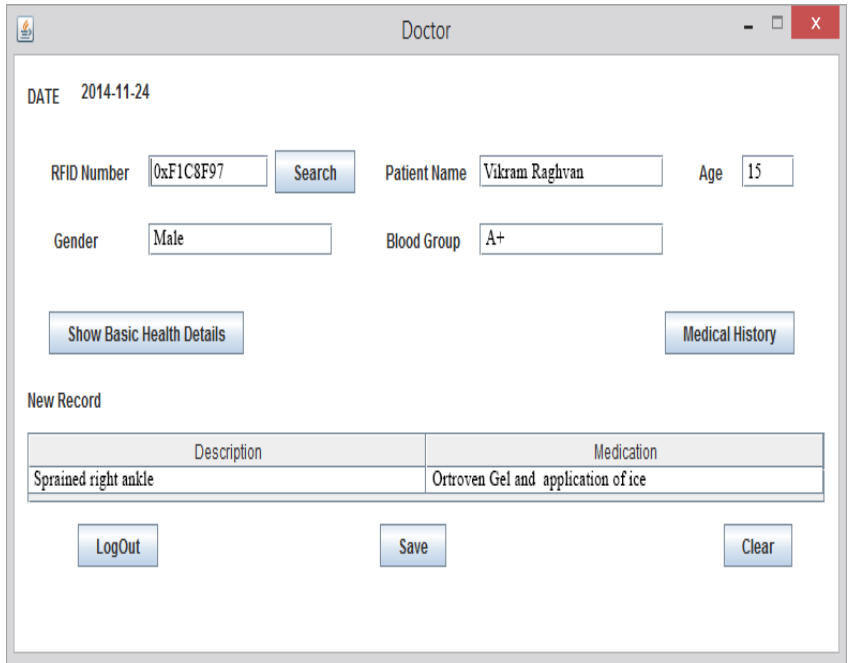

Fig 17: Doctor Frame

\subsubsection{View of Basic Health Details}

In the doctor frame (above fig), when the doctor clicks on the 'Show Basic Health Details' button, It will open this frame, in which basic details of the patient such as height, weight will be displayed.

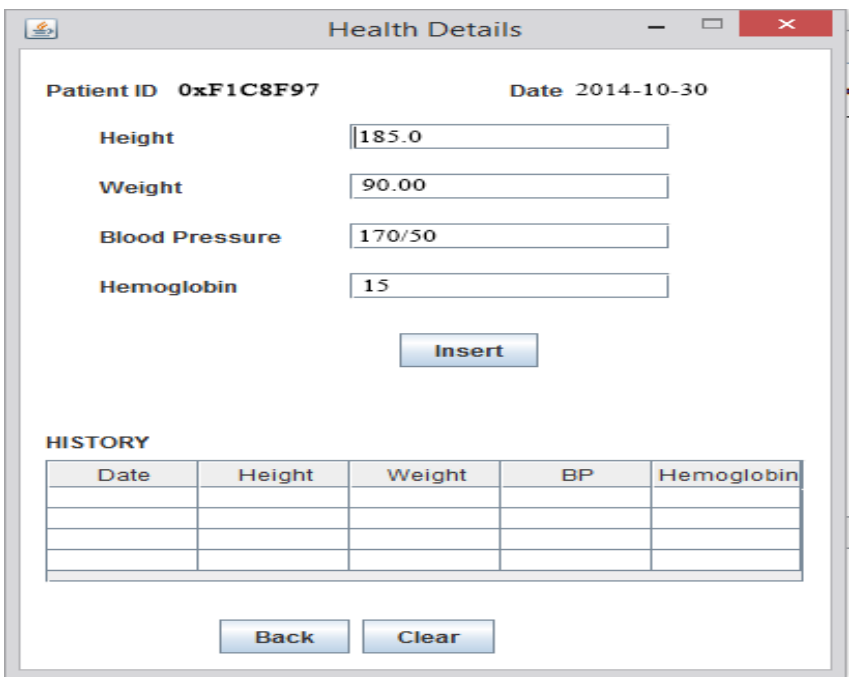

Fig 18: View Basic Health Details

\subsubsection{View Medical History}

In the doctors frame, when the doctor clicks on 'Medical History' button. It will open this frame that will show all the previous medical records of the patient prescribed by the other doctors as well as the medication. 


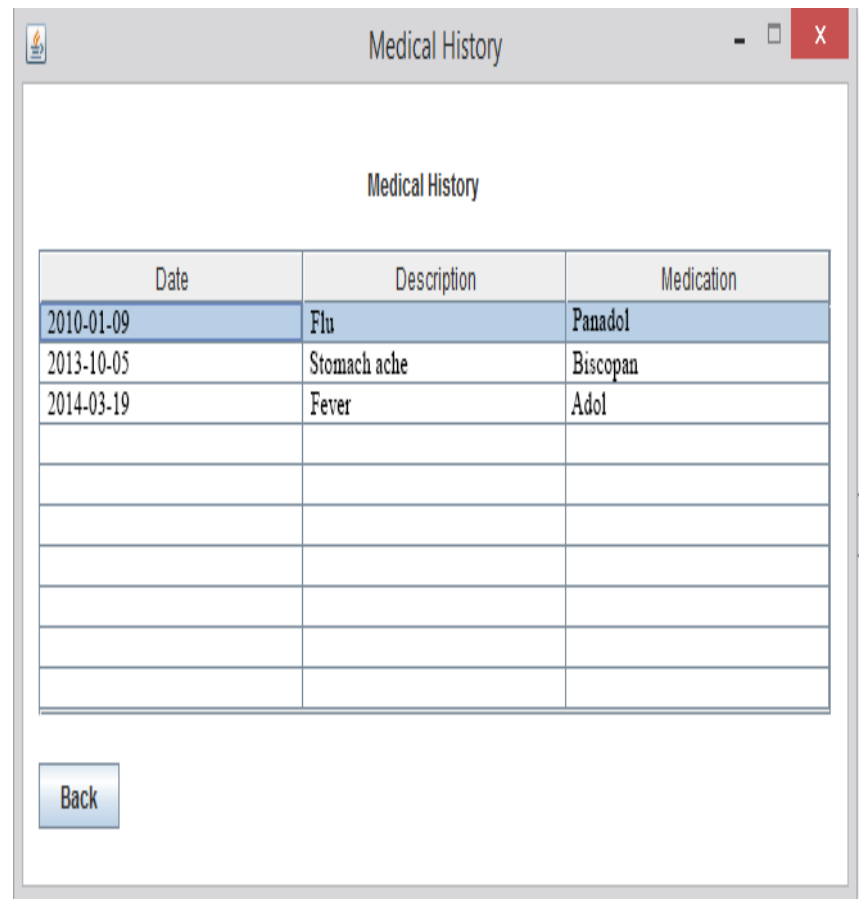

Fig 19: View Medical History

\subsubsection{Pharmacy}

The pharmacist logs into the application through the log in page. The pharmacist has to scan the patients RFID card. The medication prescribed will be displayed.

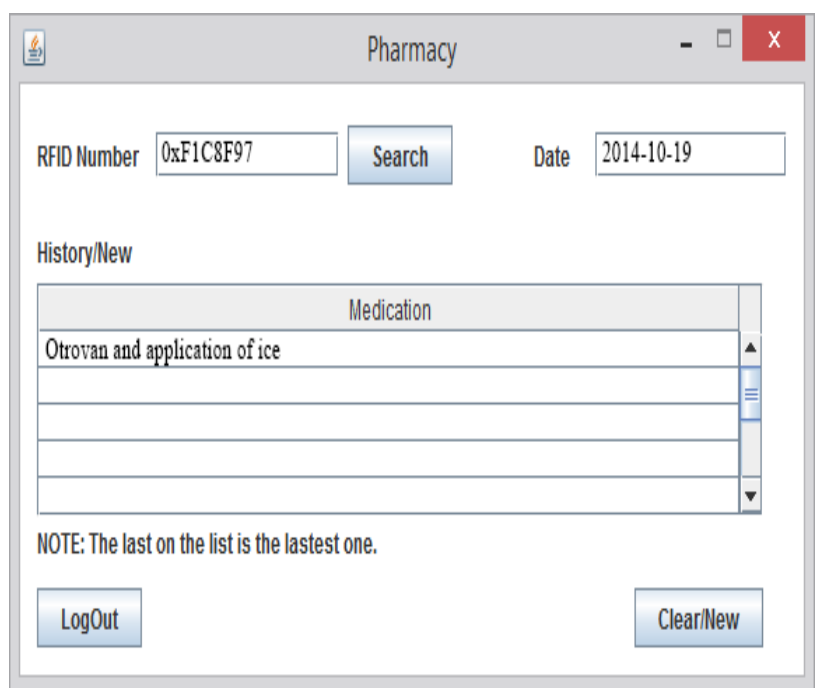

Fig 20: Pharmacy

\subsubsection{Database Administrator}

The DBA logs in through the log in frame. The DBA can add new employee, delete an employee or patient, and update the employee details.

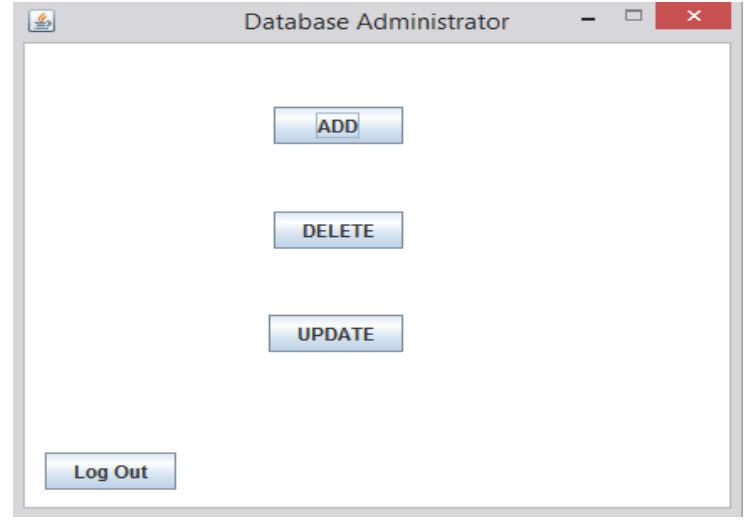

Fig 21: Database Administrator

\subsubsection{DBA - Add Employee}

The DBA can add an employee such as a doctor, receptionist, etc.

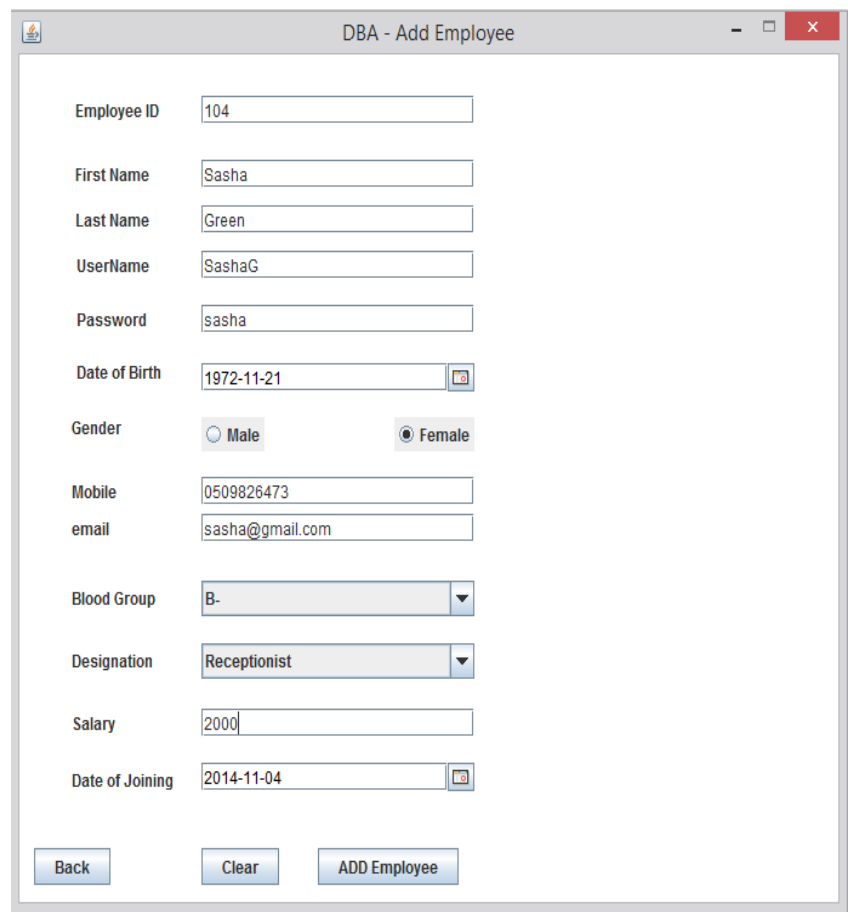

Fig 22: DBA Add Employee

\subsubsection{DBA - Delete Employee}

The DBA can delete employees using their employee ID.

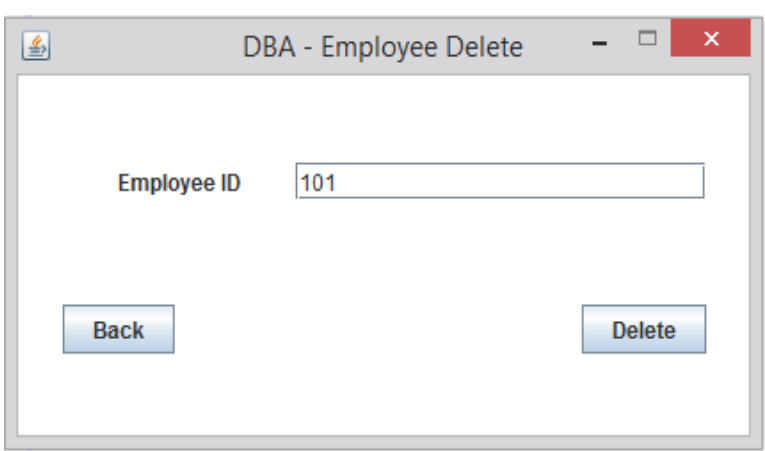

Fig 23: DBA - Delete Employee 


\subsubsection{DBA- Update}

The DBA can update the patient and employee details.

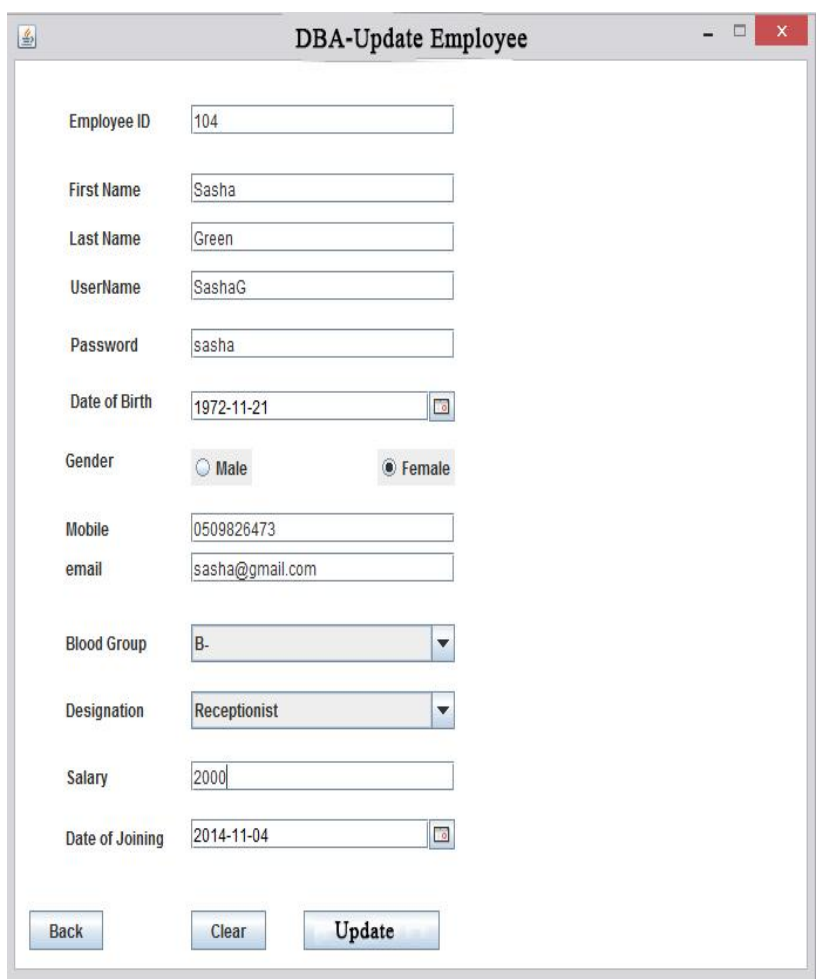

Fig 24: DBA- Update

\subsubsection{DBA Patient Update}

The DBA can update registered patients records. The RFID number can be retrieved from the reception if needed.

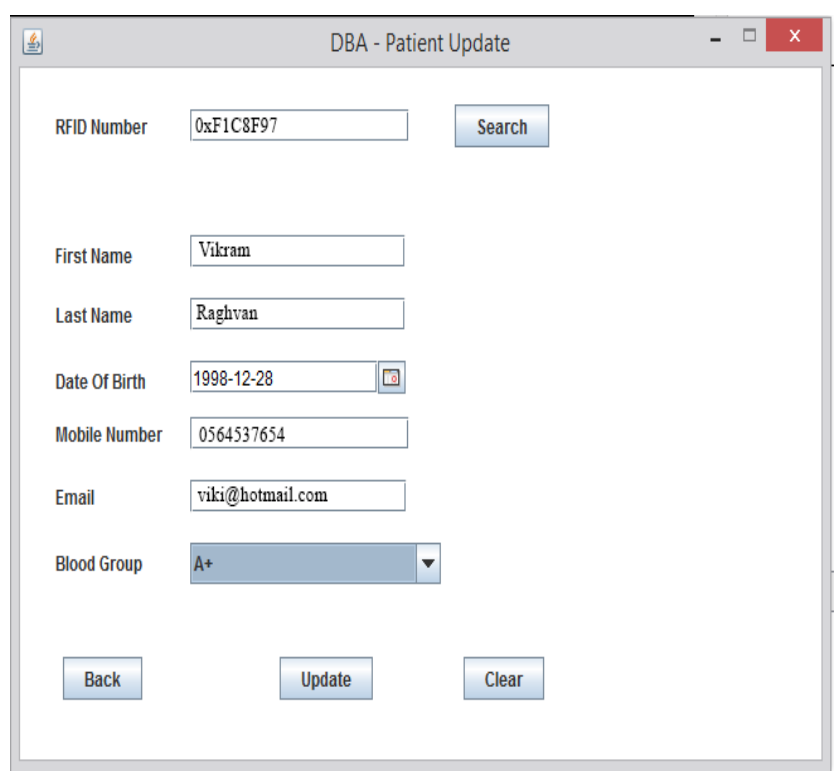

Fig 25: DBA- Patient Update

\subsubsection{DBA Employee Update}

The DBA updates employee's data using the employee update frame.

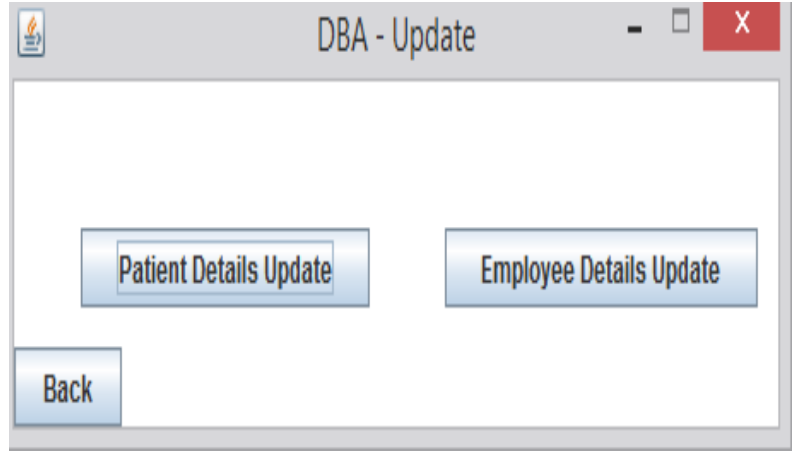

Fig 26: DBA Employee Update

\section{IMPLEMENTATION ISSUES}

During the course of the development of the application we encountered a few challenges mentioned below:

- Design Phase: Assuming the design interface of a complex hospital management system and framing it down to a few functionalities.

- RFID Connection: The RFID reader was a challenge to connect to the main software as it's an external hardware and it involved a special functions for the programming language to read the tags and for the application to recognize the reader. The manufacturing company had provided the software with no documentation, so it was difficult to understand the code [11] [12] [13][14][15].

\section{FUTURE SCOPE}

In the near future, the following additional features can be added:

- $\quad$ Biometric employee login

- $\quad$ Tracking system of inventory of medical equipments

- $\quad$ Tracking systems in child wards

- Web based application

- Mobile application

- Patients can access their medical records through mobile apps

- Generations of reports

- Statistical measurements of various data

- Integration of lab tests and scans

- Inventory for medicines and alternative medication

- Health variation tracking systems for older patients

- $\quad$ Error reporting over networks

- Email integration

- $\quad$ RFID can be replaced with NFC's using the same principle as the RFID technology

- $\quad$ Complete administrative work can be digitalized

\section{CONCLUSION}

This paper presented a concept application of RFID technology being made to be used in information systems. RFID technology has a big scope and potential. Since this technology has become more affordable, it can be implemented in a lot more ways. 
RFID is already being widely used in supply chain and logistics, but we can make use of RFID's more than that. We can even create the simplest tracking system like for our keys and glasses or even more complicated system like the home automation systems with RFID's with just a little knowledge and time.

This paper has showcased a module that can reduce waiting time in medical industry. This technology can also be implemented to reduce waiting time in other industries as well. With the implementation of this technology, firms can make more profit as there will be less waiting time and more people can be attended to in a short period of time.

\section{ACKNOWLEDGEMENTS}

I would like to express my gratitude to many people who have helped me in different ways with the development of this application. Without their continuous support and guidance, the completion of my application would be impossible.

I would like to thank Ms. Sukhwant Kaur, my application guide and my co- author of this paper for her support during the development of this application. She offered her invaluable detailed advices on grammar, organization, and the theme of the paper. Second, I would like to thank Dr. S.K. Pandey, my co-author for his continuous support and for his valuable teachings during my undergraduate. And all the faculty members for their teachings and guidance they have given to me. I will treasure this knowledge.

\section{REFERENCES}

[1] RFID Handbook ( $3^{\text {rd }}$ Edition), Klaus Finkenzeller ; John Wiley \& Sons, 2003

[2] Java Complete Reference, Herbert Schildt, McGraw Hill, 2002

[3] Development and Implementation of RFID Technology, Cristina Turcu , I-Tech Education and Publishing

[4] Sanjay Ahuja and Pavan Potti, 2010, An Introduction to RFID Technology, Scientific Research- Communication and Network 2010,2,183-186

[5] Christoph Jechlitschek, A Survey Paper on Radio Frequency Identification (RFID) Trends

[6] http://www.express.co.uk/news/uk/394773/Wespend-ten-days-each-year-in-queues

[7] http://news.err.ee/v/health/939a7bd7-9648-4a18bfa2-da9915238285

[8] http://www.emrconsultant.com/emr-educationcenter/emr-selection-and-implementation/hospitalinformation-systems-his/

[9] http://www.zebra.com/us/en/solutions/gettingstarted/rfid-printing-encoding/rfid-

basics.html\#what-is

[10] http://www.freetutes.com/systemanalysis/sa2-spiralmodel.html

[11] http://d-logic.net
[12] http://rfid.thingmagic.com/rfid-blog/bid/52243/100of-100-Uses-of-RFID

[13] http://www.slideshare.net/kataria55/srs-for-hospitalmanagement-system

[14] http://sourceforge.net/projects/hospitalmanage

[15] http://www.developer.com/net/article.php/10916_36 28811_2/RFID-Programming-Made-Simple-andcheap.htm

\section{BIOGRAPHIES}

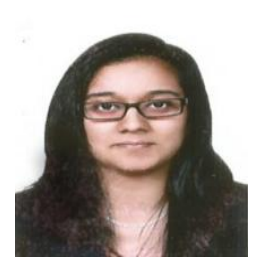

Ms. Megha Satish is a graduate from Manipal University, Dubai Campus in Bachelors of Science in Information Systems and Management (Software Management) (2014). She is certified in C, C++, Advanced Excel, IT Essentials: PC Hardware and Software, QT SDK (Nokia), ICDL, Adobe Photoshop, Adobe Flash and Digital Comic Illustration. She was also member of IEEE for 3 years. She is currently working as a graphic designer and is planning on pursuing industrial design and animation.

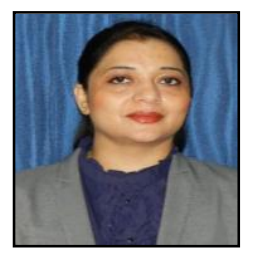

Sukhwant Kaur is currently working with Manipal University, Dubai Campus in the School of Engineering and IT. She has done B. Tech (Computer Science and Engineering) in 1999 from Punjab Technical University. She has completed M.S. (SOFTWARE SYSTEMS) in 2001 from BITS, Pilani .She has 14 years of teaching experience. She has published 20 research papers in International Journals and International and National Conferences. She is the life member of Indian Society of Technical Education (ISTE, New Delhi) and International Association of Computer Science and Informational Technology (IACSIT, Singapore). She is also the life member of Computer Society of India (CSI, India). She is member of IEEE. Her areas of interest include software engineering, Object-oriented programing concepts, Object-oriented modeling, Programming languages, Data structures, Image Processing and Design and analysis of Algorithms.

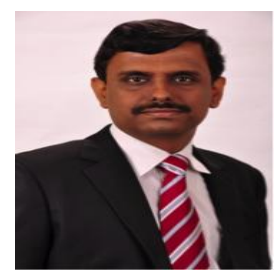

Dr. S. K. Pandey has three years of industry experience and more than 10 years of experience in the field of education and consultancy. $\mathrm{He}$ is currently the Chairperson of the School of Engineering and Information Technology at Manipal University, Dubai Campus. He is a postgraduate from the University of Allahabad, India in the field of statistics and has done his M. Tech from the Motilal Nehru Regional Engineering College, Allahabad in the field of Software Engineering. He received his Doctoral degree from Lucknow University in the field of Six Sigma. Dr. Pandey is a Certified Six Sigma Green Belt from the Indian Statistical Institute, New Delhi. His areas of interest include Quality Management, Software Engineering, Object-oriented programing concepts, Object-oriented modeling, IT project management and Lean management. Over the years, he has contributed to reputed journals and international conferences. 